\title{
PENGELOLAAN DANA PRONA DI DESA BONDALEM
}

\author{
Ngurah Yudhi Sosiawan, Laurencia Agatha Datu, I Nengah Aryantara, Desak \\ Komang Sugiarini, Komang Aryadi Saputra \\ Jurusan Akuntansi, Universitas Pendidikan Ganesha, Singaraja Bali
}

\begin{abstract}
Abstrak
Penelitian ini bertujuan untuk mengetahui bentuk kasus PRONA yang dilakukan oleh Perbekel desa Bondalem, pengelolaan dana PRONA yang di pungut di Desa Bondalem dan dan perincian dana yang disumbangkan masyarakat ke Desa. Dari hasil penelitian proyek PRONA ini sudah dilakukan sejak dahulu dan kenapa pada tahun 2012 proyek PRONA di Desa Bondalem menjadi bermasalah. Setelah melakukan penelitian ke Desa Bondalem, kami mendapatkan sedikit penjelaan mengenai system pengelolaan dana PRONA di Desa Bondalem tersebut, dimana salah satu aparat Desa yang bernama Bapak Gatot yang bertugas untuk mengelola jalannya PRONA ini, dan sekaligus beliau yang membuat kan pertanggung jawaban atas proyek PRONA ini.
\end{abstract}

Kata kunci: Dana, Pengelolaan, Prona

\begin{abstract}
This study aims to determine the form of the PRONA case conducted by the Bondalem village Perbekel, the management of the PRONA fund collected in Bondalem Village and the breakdown of funds donated by the community to the village. From the results of the research the PRONA project has been done since long ago and why in 2012 the PRONA project in Bondalem Village became problematic. After conducting research into Bondalem Village, we got a little explanation about the PRONA fund management system in Bondalem Village, where one of the Village officials named Mr. Gatot was in charge of managing the PRONA, and at the same time he was responsible for the PRONA project.
\end{abstract}

Keywords : Funds, Management, Prona

\section{Pendahuluan}

PRONA adalah salah satu bentuk kegiatan legalisasi aset dan pada hakekatnya merupakan proses administrasi pertanahan yang meliputi; adjudikasi, pendaftaran tanah sampai dengan penerbitan sertipikat/tanda bukti hak atas tanah dan diselenggarakan secara massal. PRONA dimulai sejak tahun 1981 berdasarkan Keputusan Menteri Dalam Negeri Nomor 189 Tahun 1981 tentang Proyek Operasi Nasional Agraria. Berdasarkan keputusan tersebut, Penyelenggara PRONA bertugas memproses pensertipikatan tanah secara masal sebagai perwujudan daripada program Catur Tertib di Bidang Pertanahan.

Kegiatan PRONA pada prinsipnya merupakan kegiatan pendaftaran tanah pertama kali. PRONA dilaksanakan secara terpadu dan ditujukan bagi segenap lapisan masyarakat terutama bagi golongan ekonomi lemah dan menyeselaikan secara tuntas terhadap sengketa-sengketa tanah yang bersifat strategis. Tujuan PRONA adalah memberikan pelayanan pendaftaran pertama kali dengan proses yang sederhana, mudah, cepat dan murah dalam rangka percepatan pendaftaran tanah diseluruh indonesia dengan mengutamakan desa miskin/tertinggal, daerah pertanian subur atau berkembang, daerah penyangga kota, pinggiran kota atau daerah miskin kota, daerah pengembangan ekonomi rakyat.

PRONA merupakan salah satu wujud upaya pemerintah dalam rangka meningkatkan kesejahteraan masyarakat golongan ekonomi lemah sampai dengan menengah. Biaya pengelolaan penyelenggaraan PRONA, seluruhnya dibebankan kepada rupiah murni di dalam APBN pada alokasi DIPA BPN RI. Sedangkan biaya-biaya yang berkaitan dengan alas hak/alat bukti perolehan/penguasaan tanah, patok batas, materai dan BPHTB/PPh menjadi tanggung jawab Peserta PRONA. 
Pengelolaan dana PRONA tahun 2012 di Desa Bondalem menjadi sebuah perbincangan yang hangat pada itu, hal ini dikarenakan kepala Desa Bondalem di tetapkan sebagai tersangka dan di penjarakan. Hal ini dikarenakan kesalahan yang dilakukan dalam pengelolaan dana PRONA. Dimana dana PRONA yang seharusnya di lakukan secara gratis atau Desa tidak diperbolehkan memungut dana apapun terkait pelaksanaan proyek PRONA, karena dana PRONA di tanggung oleh pemerintah, Desa hanya menyarahkan data lengkap peserta PRONA dan data tersebut akan di kirim ke BPN, maka selanjutnya PBN lah yang akan mengurus proyrh tersebut dengan bekerjasama dengan desa bersangkutan. Tetapi di Desa Bondalem kepala Desa dengan masyarakat setempat membuat sebuah kesepakatan untuk menyumbangkan beberapa dana sebagai hasil kerja aparat Desa untuk pengurusan Proyek PRONA, karena mereka tidak mendapatkan uang sepeserpun untuk penyelenggaraan proyek PRONA ini.

Nah hal inilah yang dimanfaatkan oleh oknumyang kurang sependapat dengan kepemimpinan kepala Desa tersebut ataupun lawan saat pemilihan kepala Desa yang lalu, sehingga kejadian tersebut di laporkan atas tindakan penyelewengan dana proyek PRONA karena pemunutan dana yang dilakukan menggunakan kwitansi sebagai tanda bukti maka dengan mudahnya untuk melaporkan kepala Desa Bondalem. Jadi dengan ini kami menentukan rumusan masalah sebagai berikut. Berdasarkan latar belakang di atas, penulis mengemukakan beberapa rumusan masalah yaitu Bagaimana Bentuk kasus PRONA yang dilakukan oleh Perbekel desa Bondalem, Bagaimana pengelolaan dana PRONA yang di pungut di Desa Bondalem dan Bagaimana perincian dana yang disumbangkan masyarakat ke Desa.

\section{Hasil dan Pembahasan}

\subsection{Bentuk kasus PRONA yang dilakukan oleh Perbekel desa Bondalem}

Perbekel desa Bondalem melakukan tindak pidana dalam dakwaan primair dan subsidair. Gede Rasa Dana dalam jabatannya sebagai Perbekel Desa Bondalem yang pengangkatannya berdasarkan Surat Keputusan Bupati Buleleng Nomor 141/70/HK/2011, tanggal 28 Pebruari 2011 tentang pemberhentian dan Pengangkatan Perbekel Desa Bondalem Kecamatan Tejakula Kabupaten Buleleng, pada waktu - waktu tertentu dalam tahun 2012, bertempat di Kantor Desa Bondalem Kecamatan Tejakula Kabupaten Buleleng atau setidak - tidaknya pada suatu tempat yang masih termasuk dalam daerah hukum Pengadilan Tindak Pidana Korupsi pada pengadilan Negeri Denpasar, sebagai pegawai negeri atau penyelenggara negara yang dengan maksud untuk menguntungkan diri sendiri atau orang lain secara melawan hukum atau dengan menyalahgunakan kekuasaan, memaksa seseorang memberikan sesuatu, membayar atau menerima pembayaran dengan potongan atau untuk mengerjakan sesuatu bagi dirinya sendiri. Setelah diterbitkan Keputusan Kantor Pertanahan kabupaten buleleng nomor 20/Kep-51.08/V/2012 tanggal 03 Mei 2012 tentang penunjukan Pelaksanaan teknis Kegiatan Pelaksanaan Sertifikasi Tanah PRONA di Kabupaten Buleleng, Petugas dari BPN Kabupaten Buleleng Ketut Sudira, SH melakukan sosialisasi kepada warga pemohon PRONA yang dilaksanakan di Kantor Desa Bindalem yang dihadiri oleh terdakwa selaku Perbekel Desa Bondalem dan calon Pemohon PRONA dari Desa Bondalem.

Dalam sosialisasi tersebut, petugas dari BPN kabupaten Buleleng antara lain menyampaikan kepada calon Pemohon PRONA yaitu Desa Bondalem akan mendapatkan Program PRONA tahun 2012 dan siapa tanahnya yang belum bersetifikat silahkan mendaftar di Kantor Desa atau boleh diurus sendiri dan bagi yang ikut dalam program PRONA tidak dipungut biaya di BPN selanjutnya terdakwa selaku Perbekel Bondalem juga membenarkan desa Bondalem mendapatkan program PRONA untuk tahun 2012 dan di himbau untuk warga agar melakukan pendaftaran jika belum memiliki setifikat. Perbekel desa Bondalem mengatakan kepada peserta PRONA yaitu bagi peserta PRONA yang telah mendaftar untuk menjadi peserta PRONA tahun 2012 akan dikenakan biaya rata-rata Rp. 1.000.000,-(satu juta rupiah) kalau tidak punya uang Rp. 1.000.000,-(satu juta rupiah) janganlah mencari lewat program PRONA dan bagi yang mau tetapi tidak mempunyai dana akan dibantu melalui pinjaman LPD. Padahal untuk mendaftar PRONA tidak diperlukan biaya-biaya lain atau gratis. 


\subsection{Pengelolaan Dana PRONA di Desa Bondalem}

Terkait dengan proyek PRONA di Desa Bondalem bahwa proyek PRONA ini sudah dilakukan sejak dahulu dan kenapa pada tahun 2012 proyek PRONA di Desa Bondalem menjadi bermasalah. Setelah kami melakukan penelitian ke Desa Bondalem, kami mendapatkan sedikit pen jelaan mengenai system pengelolaan dana PRONA di Desa Bondalem tersebut, dimana salah satu aparat Desa yang bernama Bapak Gatot yang bertugas untuk mengelola jalannya PRONA ini, dan sekaligus beliau yang membuat kan pertanggung jawaban atas proyek PRONA ini, beliau mengatakan bahwa "Pemerintan hanya menyaran bagi desa yang akan menyelenggarakan proyek PRONA di harapkan menyelenggarakannya secara gratis, selain itu dana dari pemerintah tidak ada yang langsung menuju desa melainkan dana tersebutjatuh ke BPN."

Jadi sesuai yang di katakana Bapak Gatot dimana dana PRONA merupakan dana dari pemerintah yang di alirkan ke BPN, bagi desa yang melakukan kegitan PRONA diharuskan melakukan secra gratis tanpa di pungut biaya apapun, selanjutnya desa yang melakukan kegiata PRONA mencari data masyarakat yang memiliki tanah tidak bersertifikat dan memiliki kemampuan ekonimi menengah kebawah. Kepala desaakan meminta kepada kepala dusun setempat untuk melakukan pencarian data tersebut. Data atau berkas yang telah di kumpulkan oleh kepala dusun setempat akan di kumpulkan kembali oleh desa, dan hasil dari pengumpulan data tersebut akan di setorkan kepada BPN.

Pengeloaan dana PRONA tahun 2012 di Desa Bondalem dimana dengan diadakannya PRONA secara gratis akan membuat masyarakat yang notabene kurang mampu tertarik untuk mengikuti proyek PRONA ini, tetapi disilain pihak aparat desa kurang puas dengan proyek yang scara gratis, karena bagi mereka proyek ini merupakan proyek yang besar dan akan membutuhkan tenaga yang banyak untuk bisa menyelesaiakn proyek ini, selain itu aparat desa juga ingin medapatkan imbalan atas keja mereka terhadap proyek PRONA ini dan masyarakat setuju untuk menyetorkan dana tersebut.

Penyetora dana tersebut di buktikan dengan kwintansi, dimana didalam kwitansi tersebut terdapar rincian bangaimana dana di alokasiakan seolah - olah bahwa desalah yang menjalankan Proyek PRONA ini. Sedangkan kenyataannya Desa hanya mengumpulkan data masyarakat yang peserta PRONA. Dari uang pungutan yang dikumpulkan dari peserta PRONA tersebut, serta perangkat desa mendapatkan uang dengan perincian sebagai berikut:

a) Terdakwa Gede Rasa Dana selaku Perbekel menerima uang sebesar Rp. 21.291.200,- ( dua puluh satu juta dua ratus sembialan puluh satu ribu dua ratus rupiah).

b) Made Arsa Mas (Almarhum) selaku Sekdes menerima uang sebesar Rp 2.000.000,- (dua juta rupiah).

c) Made Sukada AW selaku Kaur Pembangunan menerima uang sebesar Rp. 2.000.000,- ( dua juta rupiah).

d) Ketut Budi Arta selaku Kaur Pemerintahan mmenerima uang sebesar Rp. 2.000.000,- ( dua juta rupiah).

e) Gede Anta Yadnya selaku Kaur Kesra menerima ung sebesar Rp. 2.000.000,- ( dua juta rupiah).

f) Made Anggrayani selaku Kaur Umum menerima uang sebesar Rp. 2.000.000,- ( dua juta rupiah ).

g) Made Budiartini selaku Kaur Keuangan menerima uang sebesar Rp. 2.000.000,- ( dua juta rupiah).

h) Made Sukrata selaku Kadus Kelod Kangin menerima uang sebesar Rp. 1.311.528,-( satu juta tiga ratus sebelas ribu lima ratus dua puluh delapan rupiah).

i) Ketut Agus Sastrawan Sudewa selaku Kadus Kelod Kauh menerima uang sebesar Rp. 444.504,- (empat ratut empat puluh empat ribu lima ratus empat rupiah).

j) Ketut Sudiarsa selaku Kadus Kaja Kangin menerima uang sebesar Rp. 1.070.688,- ( satu juta tujuh puluh ribu enam ratus delapan puluh delapan rupiah).

k) Ketut Ariadi selaku Kadus Celagi Batur menerima uang sebesar Rp. 1.504.200,- (satu juta lima ratus empat ribu dua ratus rupiah). 
I) Nyoman Sri Tapa selaku Kadus Selombo menerima uang sebesar Rp. 1.359.696,- (satu juta tiga ratus lima puluh sembilan enam ratur sembilan puluh enam rupiah).

m) Ketut Susila selaku Kadus Jro Kuta menerima uang Rp. 2.563.896,- (dua juta lima ratus enam puluh tiga ribu delapan sembilan puluh enam rupiah).

n) Putu Parwata selaku Kadus Tegal Sari menerima uang sebesar Rp. 2.178.552,-( dua juta seratus tujuh puluh delapan limaratus ribu lima puluh dua rupiah).

o) Nyoman Widiada selaku Kadus Suksuk menerima uang sebesar Rp. 4.875.960,- ( empat juta delapan ratus tujuh puluh lima ribu sembilan ratus enam puluh rupiah).

p) Nyoman Suriada selaku Kadus Celagi Bantes menerima uang sebesar Rp.3.912.600,(tiga juta sembilan ratus dua belas ribu enam ratus rupiah)

Sudah jelas terpapar bahwa biaya-biaya yang dikeluarkan tidak sesuai dengan catatan biaya yang diperlukan. Ini menandakan bahwa Perbekel desa Bondalem melakukan korupsi terhadap dana PRONA di desa Bondalem.

\subsection{Perincian Dana yang di Pungut oleh Kepala Desa}

Tahun 2012 Desa Bonadlem mejalankan Proyek PRONA adri pemerintah, akan tetapi proyek Kepala Desa dengan masyarakat melakukan kesepakatan dimana di dalam kesepakatan itu mengatakan "bahwa masyarakat Desa Bondalem yang akan menjadi peserte PRONA melakukan pembayan sejumlah uang ke Desa untuk dapat menjalan Proyek PRONA ini." Dimana pembayaran itu di buktikan dengan sebuah kwitansi. Disi kami akan membandingakan 2 (dua) buah kwitansi sebagai bukti pembayaran atas nama I gusti nyoman arsa dan agus padmana. dengan rincian sebagai berikut:

\begin{tabular}{|l|l|c|c|}
\hline No & \multicolumn{1}{|c|}{ Buat Pembayaran } & Igst. Nyn. Arsa & Agus Padmana \\
\cline { 3 - 4 } & & Terbilang (Rp) & Terbilang (Rp) \\
\hline 1 & surat pereodik warisan & 200.000 & 200.000 \\
\hline 2 & surat kep. Perbekel & 15.000 & 15.000 \\
\hline 3 & Surat pengantar & 45.000 & 45.000 \\
\hline 4 & surat silsilah & 15.000 & 15.000 \\
\hline 5 & surat ket. Meninggal & 60.000 & 60.000 \\
\hline 6 & sumbangan NJOP & 228.000 & 286.000 \\
\hline 7 & komisi tukang ukur & 25.000 & 25.000 \\
\hline 8 & saksi perbekel atau kadus & 25.000 & 25.000 \\
\hline 9 & pantia 4 perbekel & & \\
\hline
\end{tabular}




\begin{tabular}{|l|l|c|c|}
\hline 10 & pembelian patok & 50.000 & 50.000 \\
\hline 11 & pengambilan patok & 25.000 & 25.000 \\
\hline 12 & pembelian meterai & 42.000 & 42.000 \\
\hline 13 & pengisian blangko & 60.000 & 60.000 \\
\hline 14 & aksi adat & 40.000 & 40.000 \\
\hline Jumlah & 855.000 & 913.000 \\
\hline
\end{tabular}

Nah dari hasil tabel tersebut di dapatkan jumlah yang berbeda, hasil yang berbeda ini karena adanya selisih di sumbangan NJOP. Nah kenapa hal ini bisa terjadi? Menurut keterangan yang kami minta kepada salah satu aparat Desa saat melakukan penilitian, jadi sumbangan NJOP itu berdasarkan dengan luas tanah yang dimiliki oleh peserta PRONA. Jika tanah peserta PRONA memiliki luas yang sangat luas maka sumbangan NJOP ini akan bertambah besar dan begitu juga sebaliknya.

Jadi pada kwitansi ini memiliki luas tanah yang berbeda dimana tanah Agua Padmana lebih luas di bandingkan dengan tanah milik Igst. Nyn. Arsa. Dapat di katakana bahwa ini merupakan hal yang tidak masuk akal dan melanggar yang namnya hukum. Dimana sudah di jelaskan bahwa proyek PRONA di slenggarakan secara gratis, dan jika memang ada sumbangan itu sehrusnya dalam bentuk sukarela dari masyarakat itu sendiri sebagai uang lelah dari aparat desa yang telah bekerja keras dalam proyek ini, bukan malah memanfaatkan situasi untuk melakukan penggalian dana yang besar terhadap masyarakat terutama masyarakat yang kurang mampu seharusnya bisa terbantu dengan adanya proyek yang gratis ini.

Jadi bagi masyarakat yang tidak mampu dan tidak tahu tentang hal ini mereka mau saja membayarkan sejumlah dari pada mereka harus mengurusnya sertifikat tanah sendiri. Karena bagi mreka mengurus sertifikat ini akan mengeluarkan biaya yang lebih mahal, dan tentunya mereka yang akan sibuk untuk mencari kelengkapan dari terbitnya sertifikat tanah tersebut.

\section{Simpulan Dan Saran}

Berdasarkan hasil pemaparan di atas dapat disimpulkan bahwa Perbekel desa Bondalem melakukan tindak pidana dalam dakwaan primair dan subsidair. Gede Rasa Dana dalam jabatannya sebagai Perbekel Desa Bondalem yang pengangkatannya berdasarkan Surat Keputusan Bupati Buleleng Nomor 141/70/HK/2011, tanggal 28 Pebruari 2011 tentang pemberhentian dan Pengangkatan Perbekel Desa Bondalem Kecamatan Tejakula Kabupaten Buleleng, pada waktu - waktu tertentu dalam tahun 2012, bertempat di Kantor Desa Bondalem Kecamatan Tejakula Kabupaten Buleleng atau setidak - tidaknya pada suatu tempat yang masih termasuk dalam daerah hukum Pengadilan Tindak Pidana Korupsi pada pengadilan Negeri Denpasar, sebagai pegawai negeri atau penyelenggara negara yang dengan maksud untuk menguntungkan diri sendiri atau orang lain secara melawan hukum atau dengan menyalahgunakan kekuasaan, memaksa seseorang memberikan 
sesuatu, membayar atau menerima pembayaran dengan potongan atau untuk mengerjakan sesuatu bagi dirinya sendiri.

Terkait dengan proyek PRONA di Desa Bondalem bahwa proyek PRONA ini sudah dilakukan sejak dahulu dan kenapa pada tahun 2012 proyek PRONA di Desa Bondalem menjadi bermasalah. Setelah kami melakukan penelitian ke Desa Bondalem, kami mendapatkan sedikit pen jelaan mengenai system pengelolaan dana PRONA di Desa Bondalem tersebut, dimana salah satu aparat Desa yang bernama Bapak Gatot yang bertugas untuk mengelola jalannya PRONA ini, dan sekaligus beliau yang membuat kan pertanggung jawaban atas proyek PRONA ini, beliau mengatakan bahwa "Pemerintan hanya menyaran bagi desa yang akan menyelenggarakan proyek PRONA di harapkan menyelenggarakannya secara gratis, selain itu dana dari pemerintah tidak ada yang langsung menuju desa melainkan dana tersebutjatuh ke BPN". Adapun saran dari simpulan tersebut yaitu kami untuk Desa yang melakukan kegiatan proyek PRONA ini agar senantiasa tidak melakukan tindakan korupsi, karena hal tersebut telah melanggar ketentuan Hukum dan telang menyalah gunakan jabatan.

\section{DAFTAR PUSTAKA}

http://www.antarabali.com/berita/62988/kasus-korupsi-prona-buleleng-jalani-sidang-perdana http://putusan.mahkamahagung.go.id/putusan/downloadpdf/910cfc4776ae55af9e992bfe083f 9c18/pdf 